\title{
The importance of timely treatment for quality of life and survival in patients with symptomatic spinal metastases
}

\author{
Floris R. van Tol ${ }^{1}$ (D - Karijn P. M. Suijkerbuijk ${ }^{2}$ - David Choi ${ }^{3} \cdot$ Helena M. Verkooijen $^{4}$ - F. Cumhur Oner ${ }^{1}$. \\ Jorrit-Jan Verlaan ${ }^{1,5}$
}

Received: 3 June 2020 / Revised: 25 August 2020 / Accepted: 5 September 2020 / Published online: 18 September 2020

(c) The Author(s) 2020

\begin{abstract}
Purpose A major challenge in metastatic spinal disease is timely identification of patients. Left untreated, spinal metastases may lead to gross mechanical instability and/or neurological deficits, often requiring extensive invasive surgical treatment. The aim of this cohort study was to assess the correlation between delayed treatment of patients with spinal metastases and functional performance, quality of life and survival.

Methods All patients surgically treated for metastatic spinal disease at a tertiary care facility were included for analysis. Patients who underwent elective surgery were considered as timely treated, whereas patients requiring emergency surgery were considered to be treated in a delayed fashion. EQ-5D scores, KPS scores and mortality rates were compared between the two groups.

Results A total of 317 patients (215 timely treated, 102 delayed) had survivorship data available and 202 patients (147 timely treated, 55 delayed) had clinical data available. Multivariate analyses showed delayed treatment was associated with lower EQ-5D and KPS scores and higher mortality rates, independent of confounders such as baseline EQ-5D/KPS scores, neurological status, tumor prognosis and patient age.

Conclusions The results from the present study show delayed treatment of patients with symptomatic spinal metastases has both direct and indirect adverse consequences for functional performance status, quality of life and survival. Optimization of referral pattern may accelerate the time to surgical treatment, potentially leading to better quality of life and survival.
\end{abstract}

Keywords Spinal metastases $\cdot$ Delay $\cdot$ Quality of life $\cdot$ Survival

\section{Introduction}

Primary cancer care and systemic therapy options have improved considerably over the past few decades, leading to a significant increase in survival and the subsequent

Jorrit-Jan Verlaan

j.j.verlaan@umcutrecht.nl

1 Department of Orthopedic Surgery, University Medical Center Utrecht, P.O. Box 85500 (G05.228), 3508 GA Utrecht, The Netherlands

2 Department of Medical Oncology, University Medical Center Utrecht, Utrecht, The Netherlands

3 Department of Neurosurgery, The National Hospital for Neurology and Neurosurgery, London, UK

4 Imaging Division, University Medical Center Utrecht, Utrecht, The Netherlands

5 University of Utrecht, Utrecht, The Netherlands prevalence of patients with metastatic disease [1]. One of the most debilitating complications of advanced cancer is metastatic spinal disease, which currently occurs in approximately $20 \%$ of all oncological patients [2,3]. A major challenge in metastatic spinal disease is that presenting symptoms can be very non-specific, leading to difficulties in distinguishing between patients presenting with symptoms of metastatic spinal disease from patients with other, nonmalignant causes of neck or back pain [4]. Because non-specific back pain is one of the most common conditions in middle aged people, and is generally regarded as self-limiting, patients with spinal metastases are at risk for consequential delays in diagnosis, referral and treatment $[5,6]$.

In the early stages of metastatic spinal disease, patients can usually be treated with non-surgical methods such as systemic anti-cancer treatment or palliative radiotherapy [7]. Left untreated, however, spinal metastases may continue to compromise bone integrity or cause intractable pain, 
requiring (stabilizing) surgical procedures [8]. At a more advanced stage, spinal metastases may also cause neurological symptoms, commonly requiring large open surgical procedures to decompress the involved neural structures [9, 10]. Consequently, the timing of treatment is considered an important factor in determining treatment outcome.

We previously reported on delayed surgical treatment of patients with spinal metastases being associated with worse surgical and postoperative outcomes, showing increased surgical duration, blood loss, length of stay (LOS) and postoperative adverse events [11]. The effects of delayed treatment on functional status, perceived quality of life and survival however remains largely unclear.

The primary aim of the present prospective study was to assess the relationship between delayed treatment (i.e., requiring emergency surgery) and functional status, QoL and survival in patients surgically treated for symptomatic spinal metastases. The secondary aim was to assess how various factors of delayed treatment (e.g. neurological deficits, emergency surgery) might have contributed to the aforementioned outcome parameters independently.

\section{Materials and methods}

All patients surgically treated between March 2009 and July 2018 for symptomatic spinal metastases or spinal localizations of hematologic malignancies at a single tertiary spine center were eligible for inclusion. A waiver of informed consent was approved for this study by the institutional review board. In cases where metastases originated from an unknown primary tumor, tumor histology was determined at a later stage from intra-operative biopsies. Based on the clinical profile of their primary tumor, patients were classified as favorable, moderate or unfavorable, in line with the median overall survival as previously described by Bollen et al. [12] If the primary tumor remained unknown postoperatively, the prognosis was classified as unfavorable. Patients were deemed eligible for surgical treatment if the estimated survival exceeded 3 months as determined by frequently cited prognostic models and preoperative clinical assessment by the treating team consisting of a spine surgeon, oncologist and radiation oncologist [13]. Mechanical pain, gross radiographic spinal instability and/or neurological deficits were the major indications for surgical treatment. The attending/ treating spine surgeon decided on the surgical approach and technique for each individual case combining common scoring systems (Neurologic, Oncologic, Mechanic, Systemic (NOMS): Frankel classification for neurological status combined with Bilsky score for degree of epidural compression; Bollen classification for tumor biology; Spinal Instability and Neoplastic Score (SINS) for spinal stability and KPS for general patient condition) [14] into a uniform treatment strategy $[10,13]$. During the study period, there were no major changes in treatment policy in this center.

Demographic data including age and sex were recorded into the dataset. The American Society of Anesthesiologists (ASA)-classification, Frankel grade, mobility score, Karnofsky Performance Score (KPS) and EQ-5D scores were extracted from patient's medical records. The surgical urgency was assessed and recorded by the treating spine surgeon preoperatively in accordance with internationally established guidelines [15]. KPS scores and EQ-5D scores were obtained at 3 and 6 months follow-up. Based on the preferred timing of surgery after initial presentation at the spine unit, patients were categorized into 'timely treatment' or 'delayed treatment', to account for the full unfavorable chain of events accompanying emergency surgery. 'Delayed treatment' was defined as requiring surgical treatment within 3 days. 'Timely treatment' was defined as being eligible for planned intervention more than 3 days after initial surgical presentation. The three-day cutoff was chosen in accordance with the protocol used by the Global Spine Tumor Study Group [16].

\section{Statistical analysis}

For continuous data, means, standard deviations (SD), medians and interquartile range (IQR) were used. For categorical data frequencies were used. In our multivariate models, KPS and EQ-5D were treated as a continuous variable in accordance with previous literature stating ordinal data with 5 or more categories does not compromise the integrity of linear models [17-19]. To compare the two patient groups at baseline unpaired $t$ tests were used for continuous data and Chi-squared tests for categorical data. To assess the relationship between delayed treatment and EQ-5D and KPS scores at the two follow-up moments, independent of known prognostics, generalized estimating equations (GEE's) were used duplicating cases based on the two follow-up moments. Due to multicollinearity the authors favored the 3-point mobility score over the Frankel grade since it better reflects the functional status of the patient. Any interaction between timely or delayed treatment and the first or second follow-up moment were assessed by adding an interaction term to the GEE models. To assess the effect of loss to follow-up between 3 and 6 months on outcome parameters at 6 months, we compared KPS and EQ-5D scores at three months between patients available for analysis at 6 months and those lost to follow-up between 3 and 6 months. Kaplan-Meier curves were created to analyze 1 year survival in both treatment groups. Log-rank tests were used to test for statistical significance. To analyze the relationship between the treatment category and survival, independent of known prognostic factors such as patient mobility, tumor prognosis and patient age, 
Cox proportional hazards models were used. All analyses were performed using IBM SPSS Statistics.

\section{Results}

In total, 317 patients were eligible for inclusion of which 215 underwent timely treatment and 102 delayed treatment. Survivorship data was available for all patients and follow-up data on EQ-5D and KPS at either 3- or 6-months was available for 202 patients (147 timely treated and 55 delayed treatment patients) of the 238 patients still alive at 6 months. Baseline demographics can be found in Table 1.

Figure 1 shows EQ-5D scores for both groups at baseline, three months and six months follow-up. For timely treated patients, the median (IQR) EQ-5D was $0.57(0.24-0.73)$ at baseline $(n=143), 0.73(0.57-0.81)$ at 3 months $(n=125)$ and $0.78(0.57-0.89)$ at 6 months $(n=51)$. For delayed treatment patients, the median (IQR) EQ-5D was $0.24(0.1-0.33)$ at baseline $(n=50), 0.48$ $(0.26-0.74)$ at 3 months $(n=36)$ and $0.73(0.37-0.85)$ at 6 months $(n=20)$. The difference between timely treated and delayed treated patients was statistically significant at baseline and three months. Generalized estimating equations showed a time-dependent negative effect of delayed treatment on the follow-up EQ-5D scores, where delayed patients had lower EQ-5D scores at 3 months, but not at 6 months, independent of the preoperative EQ-5D score, mobility score, tumor prognosis and patient age (Table 2).

Figure 2 shows KPS scores for both groups at baseline, three months and six months follow-up. For timely treated patients, the median (IQR) KPS was 70 (60-80) at baseline $(n=147), 80(80-80)$ at 3 months $(n=135)$ and $80(70-90)$ at 6 months $(n=53)$. For delayed treatment patients, the median (SD) KPS was 60 (50-70) at baseline $(n=55), 70(60-70)$ at 3 months $(n=49)$ and $70(60-80)$ at 6 months $(n=27)$. The difference between timely treated and delayed treatment patients was statistically significant for all three time points. Generalized estimating equations showed a time-independent negative effect of delayed treatment on the follow-up KPS scores, independent of the preoperative KPS score, mobility score, tumor prognosis and patient age (Table 3). Sensitivity analyses showed no significant differences in KPS and EQ-5D scores at 3 months between patients available for analysis at 6 months and those lost to follow-up or deceased.

Out of all patients, 44 (13.9\%) died within 3 months, and $119(37.5 \%)$ within 1 year. One-year survival was $70.1 \%$ in the timely treated group versus $50.9 \%$ in the delayed treatment group ( $p=0.001$, Fig. 3). Cox proportional hazards analysis showed that delayed treatment was associated with lower survival rates independent of the preoperative mobility score, tumor prognosis and patient age (Table 4).

\section{Discussion}

In the current study, 215 patients underwent timely treatment (i.e., were able to undergo planned surgery) and 102 underwent delayed treatment (i.e., required emergency surgery). Delayed treatment was associated with greater neurological deficits at baseline, as expected. However, no significant differences were found in patient- and diseaserelated parameters. These findings suggest that the largest difference between these groups lies in the timing of their surgical treatment. Multivariate analyses showed that followup EQ-5D, KPS and survival rates were lower in the delayed treatment group, independent of other known prognostic factors including the baseline EQ-5D/KPS, neurological status, primary tumor and patient age. Even though the lower neurological scores in the delayed treatment group are known to have a negative effect on KPS, EQ-5D and survival, these findings suggest that the resulting (delayed) treatment regimen further affected patient outcome.

Delayed treatment was associated with a median KPS of 70 compared to a median KPS of 80 in timely treated patients at both 3- and 6-months follow-up. Patients with a KPS of 80 can engage in normal activity, albeit with some difficulty, however patients with a KPS of 70 are not capable of normal activity or work. Therefore, the observed difference between the two groups can be considered highly relevant from a clinical perspective. Both treatment groups showed comparable absolute increases in KPS scores at three and six months compared to baseline scores, perpetuating the inferior KPS scores in the delayed treatment group. These findings are in line with an earlier study reporting on patients with cervical metastases either operated on through an anterior approach (in case of a single metastasis) or through a posterior approach combined with decompression [20]. Both groups had comparable absolute improvements in KPS of approximately 10 points, even though the group requiring decompressive surgery had considerably lower baseline scores. For EQ-5D scores in the present study, the differences between the two groups which were present at baseline persisted at 3 months, but not at 6 months. This is furthermore supported by a study by de Ruiter et al. [21] where patients requiring either posterior stabilization without decompression or a corpectomy did not show an increase in EQ-5D scores after 3 months. In contrast, a third group of patients requiring both posterior decompression and stabilization showed a similar increase between their baseline 
Table 1 Demographics for patients in both treatment groups

\begin{tabular}{|c|c|c|c|}
\hline & Timely Treated $n=147$ & Delayed $n=55$ & $p$ value \\
\hline Mean age, years (SD) & $61.7(11.7)$ & $61.8(11.6)$ & 0.976 \\
\hline Gender, male (\%) & $75(51.0 \%)$ & $26(47.3 \%)$ & 0.758 \\
\hline ASA, $n(\%)$ & & & 0.402 \\
\hline 1 & $32(21.8 \%)$ & $6(10.9 \%)$ & \\
\hline 2 & $84(57.1 \%)$ & $37(67.3 \%)$ & \\
\hline 3 & $31(21.1 \%)$ & $12(21.8 \%)$ & \\
\hline Tumor Histology, $n(\%)$ & & & 0.787 \\
\hline Bladder & $2(1.4 \%)$ & $0(0.0 \%)$ & \\
\hline Breast & $38(26.0 \%)$ & $14(25.5 \%)$ & \\
\hline Cervicouterine & $3(2.1 \%)$ & $1(1.8 \%)$ & \\
\hline Gastrointestinal & $6(4.1 \%)$ & $4(7.3 \%)$ & \\
\hline Lung & $12(8.2 \%)$ & $7(12.7 \%)$ & \\
\hline Lymphoma & $6(4.1 \%)$ & $5(9.1 \%)$ & \\
\hline Melanoma & $2(1.4 \%)$ & $0(0.0 \%)$ & \\
\hline Myeloma & $25(17.1 \%)$ & $10(18.2 \%)$ & \\
\hline Plasmacytoma & $5(3.4 \%)$ & $4(7.3 \%)$ & \\
\hline Prostate & $11(7.5 \%)$ & $6(10.9 \%)$ & \\
\hline Renal & $19(3.0 \%)$ & $2(3.6 \%)$ & \\
\hline Sarcoma & $2(1.4 \%)$ & $0(0.0 \%)$ & \\
\hline Thyroid & $1(0.7 \%)$ & $0(0.0 \%)$ & \\
\hline Other & $9(6.2 \%)$ & $1(1.8 \%)$ & \\
\hline Unknown & $5(3.4 \%)$ & $1(1.8 \%)$ & \\
\hline Tumor favourability, $n(\%)$ & & & 0.830 \\
\hline Favorable & $42(29.0 \%)$ & $20(36.4 \%)$ & \\
\hline Moderate & $55(37.9 \%)$ & $21(38.2 \%)$ & \\
\hline Unfavorable & $48(33.1 \%)$ & $14(25.5 \%)$ & \\
\hline Chemotherapy past year, $n(\%)$ & & & 0.010 \\
\hline Yes & $14(9.7 \%)$ & $3(5.6 \%)$ & \\
\hline No & $130(90.3 \%)$ & $51(94.4 \%)$ & \\
\hline Radiotherapy past year, $n(\%)$ & & & 0.754 \\
\hline Yes & $23(15.9 \%)$ & $7(13.2 \%)$ & \\
\hline No & $122(84.1 \%)$ & $46(86.8 \%)$ & \\
\hline EQ5D, median (IQR) & $0.57(0.24-0.73)$ & $0.24(0.12-0.33)$ & $<0.001$ \\
\hline KPS*, median (IQR) & $70(60-80)$ & $60(50-70)$ & $<0.001$ \\
\hline VAS pain, mean (SD) & $4.7(2.3)$ & $4.7(2.4)$ & 0.928 \\
\hline Frankel on entry, $n(\%)$ & & & $<0.001$ \\
\hline A & $0(0.0 \%)$ & $2(3.6 \%)$ & \\
\hline $\mathrm{B}$ & $0(0.0 \%)$ & $2(3.6 \%)$ & \\
\hline $\mathrm{C}$ & $2(1.4 \%)$ & $13(23.6 \%)$ & \\
\hline $\mathrm{D}$ & $20(13.6 \%)$ & $26(47.3 \%)$ & \\
\hline $\mathrm{E}$ & $125(85.0 \%)$ & $12(21.8 \%)$ & \\
\hline Mobility on entry, $n(\%)$ & & & 0.001 \\
\hline Normal & $112(76.2 \%)$ & $22(15.05)$ & \\
\hline Uses one crutch & $1(0.7 \%)$ & $0(0.0 \%)$ & \\
\hline Uses walker or two crutches & $8(5.4 \%)$ & $4(2.7 \%)$ & \\
\hline Confined to wheelchair & $6(4.1 \%)$ & $5(3.4 \%)$ & \\
\hline Confined to bed & $20(13.6 \%)$ & $24(16.3 \%)$ & \\
\hline Other metastases, $n(\%)$ & & & 0.761 \\
\hline Yes & $42(28.6 \%)$ & $13(23.6 \%)$ & \\
\hline No & $105(71.4 \%)$ & $42(76.4 \%)$ & \\
\hline Number of affected levels $n(\%)$ & & & 0.337 \\
\hline
\end{tabular}


Table 1 (continued)

\begin{tabular}{llll}
\hline & Timely Treated $n=147$ & Delayed $n=55$ & $p$ value \\
\hline 1 & $71(48.3 \%)$ & $23(41.8 \%)$ & \\
2 & $26(17.7 \%)$ & $6(10.9 \%)$ & \\
3 & $17(11.6 \%)$ & $9(16.4 \%)$ & \\
$\geq 4$ & $33(22.4 \%)$ & $17(30.9 \%)$ & \\
Surgical procedure & & & \\
Cement augmentation & $4(2.7 \%)$ & 0.001 \\
Decompression & $0(0.0 \%)$ & $1(1.9 \%)$ & \\
Percutaneous fixation & $69(47.3 \%)$ & $6(11.1 \%)$ & \\
Open spondylodesis without decompression & $34(23.3 \%)$ & $5(9.3 \%)$ & \\
Open spondylodesis with decompression & $22(15.1 \%)$ & $38(70.4 \%)$ & \\
Tumor resection & $17(11.6 \%)$ & $4(7.4 \%)$ & \\
\hline
\end{tabular}

*Karnofsky Performance Score

\section{Median (IQR) EQ-5D scores for delayed and timely treatment}

- Timely treatment

- Delayed treatment

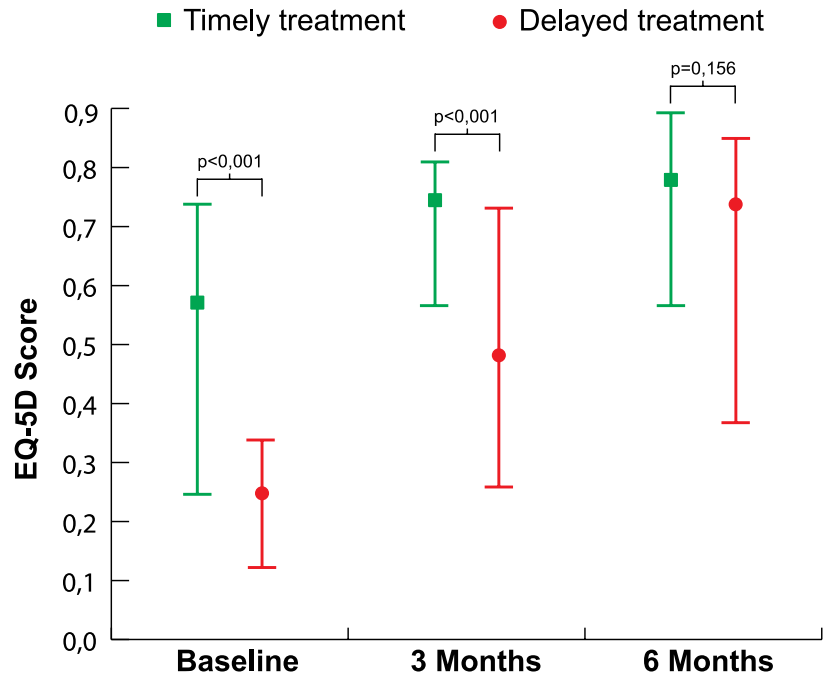

Fig. 1 Medan (IQR) EQ-5D scores for timely treated patients and delayed patients at baseline, 3 months and 6 months follow-up

and 3 month scores, but also a slight increase between 3 and 6 month scores. This may be partially attributed to a ceiling effect in the timely treated group, not allowing for more improvement in their utility scores and/or performance status. Another common phenomenon in patients with neurological deficits is a so-called response shift, which is also frequently observed in patients with traumatic spinal cord injury [22]. In these cases, patients show adaptation to their neurological condition and report increases in perceived QoL despite limited improvements in objective functioning. This is also reflected in the current study, where generalized estimating equations showed that delayed treatment was independently correlated with follow-up KPS and EQ-5D scores after correction for confounding factors, however for EQ-5D this was a time-dependent correlation not persisting at 6 months follow-up. This may also partly explain why the differences in EQ-5D scores between the two treatment groups became non-significant over time.

Timely treatment was associated with a 1 year survival of $70.1 \%$ compared with a 1 year survival of $50.9 \%$ for delayed treatment. A Cox proportional hazards model showed that the negative effects of delayed treatment on survival remained present independent of known prognostic factors such as preoperative mobility, tumor prognosis and patient age. Lower pre-operative mobility scores were also independently associated with worse 1 year survival, which is in line with previous literature [23, 24]. Since both neurological symptoms, as well as the subsequent emergency surgery, are often caused by delays, this suggests a considerable effect of delays on patient survival.

Symptomatic spinal metastases occur in approximately $10 \%$ of all oncological patients, but not all oncological health-care providers are fully familiar with the management of metastatic spinal disease. Nonetheless, for the timely treatment of patients, specialized care-centers rely heavily on the efficiency of referral patterns within primary and secondary care. Even though treatment for metastatic spinal disease is becoming increasingly effective, an important factor in determining treatment outcome is the patient's pre-treatment condition. Consequently, it is imperative to combat the negative effects of delay on the quality of life and survival of patients.

Delayed recognition of metastatic spinal disease often leads to a chain of unfavorable events which may negatively influence patient outcome. Firstly, the epidural spinal cord compression has a direct negative effects on patient outcome and survival [8, 21, 25, 26]. Furthermore, the subsequent emergent surgical procedures required to decompress the neural structures are more invasive than simple (for example, percutaneous) stabilizing procedures, used in patients without symptomatic spinal cord compression, as is also reflected in the current study. Due to their more demanding nature, 
Table 2 Generalized Estimating Equations for follow-up EQ-5D scores independent of preoperative EQ-5D score, mobility score, tumor prognosis and patient age. To assess if the correlation between delayed treatment and EQ-5D scores differed at 3 and 6 months follow-up, a second analysis was performed with an interaction term between the follow-up moment and the treatment category

\begin{tabular}{|c|c|c|}
\hline & $\begin{array}{l}\text { EQ-5D } \\
\text { Utility score (CI) }\end{array}$ & $\begin{array}{l}n=166 \\
p \text { value }\end{array}$ \\
\hline \multicolumn{3}{|l|}{ Without interaction term } \\
\hline Intercept & $0.88(0.65-1.00)^{*}$ & $<0.001$ \\
\hline \multicolumn{3}{|l|}{ Follow-up moment } \\
\hline 3 months & Reference & \\
\hline 6 months & $0.05(0.00-0.11)$ & 0.065 \\
\hline \multicolumn{3}{|l|}{ Pre-operative EQ-5D } \\
\hline Per point & $0.19(0.05-0.33)$ & 0.008 \\
\hline \multicolumn{3}{|l|}{ Treatment category } \\
\hline Timely treated & Reference & \\
\hline Delayed & $-0.08(-0.18-0.01)$ & 0.078 \\
\hline \multicolumn{3}{|l|}{ Mobility score } \\
\hline Unassisted & Reference & \\
\hline Assisted & $-0.03(-0.16-0.09)$ & 0.615 \\
\hline Unable & $-0.07(-0.18-0.05)$ & 0.260 \\
\hline \multicolumn{3}{|l|}{ Tumor prognosis } \\
\hline Favorable & Reference & \\
\hline Moderate & $-0.03(-0.12-0.06)$ & 0.646 \\
\hline Unfavorable & $-0.12(-0.21$ to $-0,03)$ & 0.013 \\
\hline \multicolumn{3}{|l|}{ Age } \\
\hline Per year & $0.00(-0.01-0.00)$ & 0.013 \\
\hline \multicolumn{3}{|l|}{ With interaction term } \\
\hline Intercept & $0.9(0.66-1.00)^{*}$ & $<0.001$ \\
\hline \multicolumn{3}{|l|}{ Follow-up moment } \\
\hline 3 months & Reference & \\
\hline 6 months & $0.01(-0.05-0.08)$ & 0.709 \\
\hline \multicolumn{3}{|l|}{ Pre-operative EQ-5D } \\
\hline Per point & $0.19(0.05-0.33)$ & 0.008 \\
\hline \multicolumn{3}{|l|}{ Treatment category } \\
\hline Timely treated & Reference & \\
\hline Delayed & $-0.14(-0.24$ to -0.03$)$ & 0.012 \\
\hline \multicolumn{3}{|l|}{ Mobility score } \\
\hline Unassisted & Reference & \\
\hline Assisted & $-0.03(-0.15-0.10)$ & 0.658 \\
\hline Unable & $-0.06(-0.18$ to 0.05$)$ & 0.274 \\
\hline \multicolumn{3}{|l|}{ Tumor prognosis } \\
\hline Favorable & Reference & \\
\hline Moderate & $-0.04(-0.13-0.05)$ & 0.418 \\
\hline Unfavorable & $-0.13(-0.22$ to $-0,03)$ & 0.009 \\
\hline \multicolumn{3}{|l|}{ Age } \\
\hline Per year & $0.00(-0.01-0.00)$ & 0.012 \\
\hline Interaction term & $0.15(0.03-0.28)$ & 0.016 \\
\hline 6 months + delayed treatment & $0.15(0.03-0.28)$ & 0.016 \\
\hline
\end{tabular}

*Rounded down to clinically appropriate values

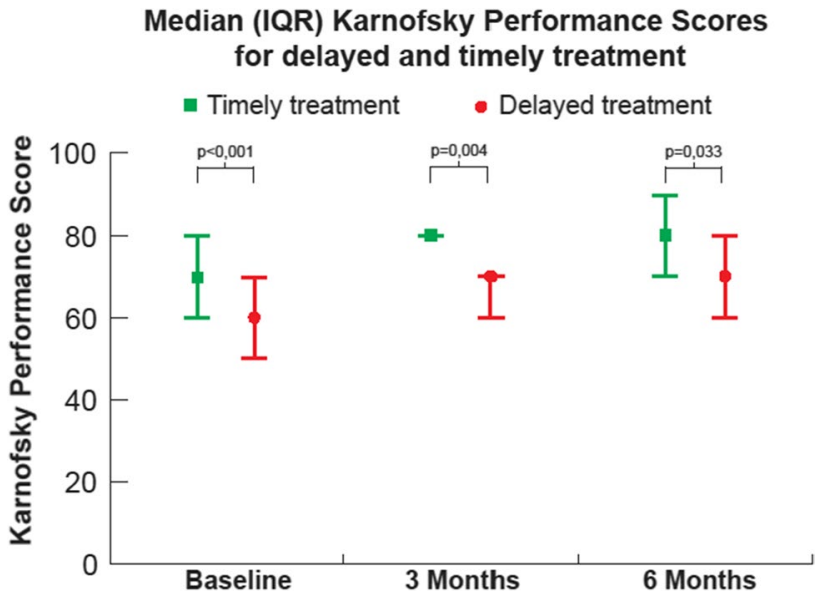

Fig. 2 Median (IQR) KPS scores for timely treated patients and delayed patients at baseline, 3 months and 6 months follow-up

these decompressive surgical procedures can also lead to inferior patient outcomes [21]. In addition to neurological deficit and the subsequent invasive surgical treatment necessary, other factors associated with emergency treatment, such as a more limited window for adequate patient work-up and/or having to perform surgery outside office hours with a potentially less experienced team, may further negatively influence patient outcome [27, 28].

Several limitations apply to this study. First, even though no differences between the two groups were found in terms of primary tumor types, no further details on the molecular subtype and clinical characteristics of tumors were available. We cannot fully exclude that patients presenting with an indication for emergency surgery had more aggressive tumor biology. However, because differences in prognoses will be more outspoken between different primary tumor types than differences within a single tumor type, the authors believe that the results adequately represent the effect of delayed treatment. Second, because the timing of the surgery was left to the discretion of the attending surgeon, this process may be subject to some variability. However, all surgeons involved in this study are part of the same spinal unit and adhere to the same basic principles in the treatment of patients with spinal metastases (the NOMS-framework) [10]. Finally, there was some drop-out between the 3- and 6-months follow-up points, partially caused by loss to follow-up and partially by mortality. Sensitivity analyses comparing KPS and EQ-5D at 3 months between patients with and without data available at 6 months showed no significant differences, therefore an effect of bias due to of loss to follow-up on our results is likely limited. 
Table 3 Generalized Estimating Equations for follow-up KPS scores independent of preoperative KPS score, mobility score, tumor prognosis and patient age. To assess if the correlation between delayed treatment and KPS scores differed at 3 and 6 months follow-up, a second analysis was performed with an interaction term between the follow-up moment and the treatment category

\begin{tabular}{|c|c|c|}
\hline & $\begin{array}{l}\text { KPS } \\
\text { Score (CI) }\end{array}$ & $\begin{array}{l}n=192 \\
p \text { value }\end{array}$ \\
\hline \multicolumn{3}{|l|}{ Without interaction term } \\
\hline Intercept & $75.7(60.1-89.3)$ & $<0.001$ \\
\hline \multicolumn{3}{|l|}{ Follow-up moment } \\
\hline 3 months & Reference & \\
\hline 6 months & $4.6(2.3-6.9)$ & $<0.001$ \\
\hline \multicolumn{3}{|l|}{ Pre-operative KPS } \\
\hline Per point & $0.2(0.0-0.3)$ & 0.012 \\
\hline \multicolumn{3}{|l|}{ Treatment category } \\
\hline Timely treated & Reference & \\
\hline Delayed & $-7.7(-11.2$ to -4.2$)$ & $<0.001$ \\
\hline \multicolumn{3}{|l|}{ Mobility score } \\
\hline Unassisted & Reference & \\
\hline Assisted & $-2.6(-7.8-2.6)$ & 0.318 \\
\hline Unable & $-2.1(-7.2-3.0)$ & 0.412 \\
\hline \multicolumn{3}{|l|}{ Tumor prognosis } \\
\hline Favorable & Reference & 0.851 \\
\hline Moderate & $0.3(-3.2-3.9)$ & 0.168 \\
\hline Unfavorable & $-2.6(-6.4-1.1)$ & \\
\hline \multicolumn{3}{|l|}{ Age } \\
\hline Per year & $-0.2(-0.3$ to -0.0$)$ & 0.012 \\
\hline \multicolumn{3}{|l|}{ With interaction term } \\
\hline Intercept & $74.7(60.1-89.3)$ & $<0.001$ \\
\hline \multicolumn{3}{|l|}{ Follow-up moment } \\
\hline 3 months & Reference & \\
\hline 6 months & $3.3(0.6-6.0)$ & 0.017 \\
\hline \multicolumn{3}{|l|}{ Pre-operative KPS } \\
\hline Per point & $0.2(0.0-0.3)$ & 0.013 \\
\hline \multicolumn{3}{|l|}{ Treatment category } \\
\hline Timely treated & Reference & \\
\hline Delayed & $-8.8(-12.6$ to -5.0$)$ & $<0.001$ \\
\hline \multicolumn{3}{|l|}{ Mobility score } \\
\hline Unassisted & Reference & \\
\hline Assisted & $-2.5(-7.7-2.7)$ & 0.345 \\
\hline Unable & $-2.2(-7.3-3.0)$ & 0.405 \\
\hline \multicolumn{3}{|l|}{ Tumor prognosis } \\
\hline Favorable & Reference & \\
\hline Moderate & $0.2(-3.4-3.8)$ & 0.917 \\
\hline Unfavorable & $-2.9(-6.7-0.9)$ & 0.133 \\
\hline \multicolumn{3}{|l|}{ Age } \\
\hline Per year & $-0.2(-0.3$ to -0.0$)$ & 0.012 \\
\hline \multicolumn{3}{|l|}{ Interaction term } \\
\hline 6 months + delayed treatment & $3.9(-0.9-8.6)$ & 0.113 \\
\hline
\end{tabular}

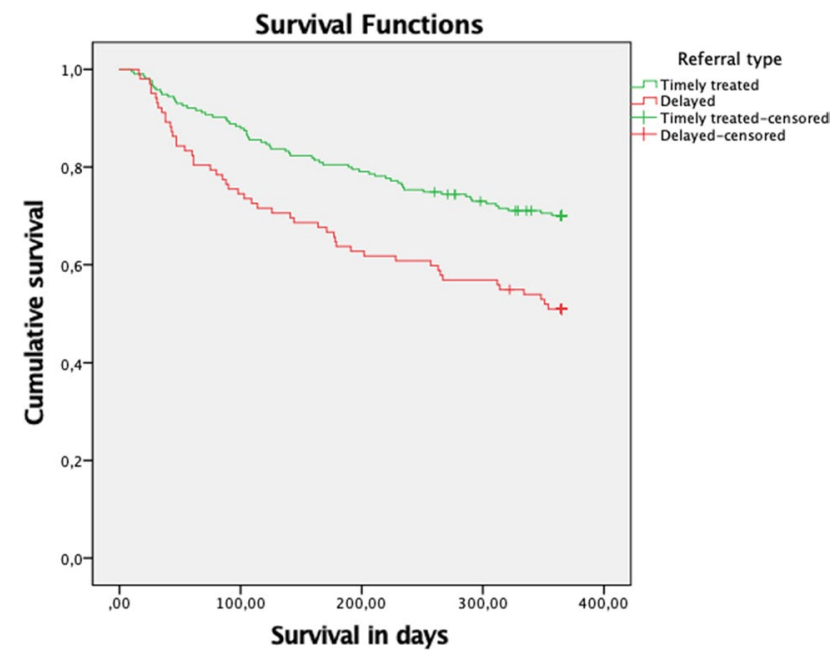

Fig. 3 Survival curves for timely treated $(n=215)$ and delayed patients $(n=102)$ patients. One-year survival was $70.1 \%$ for timely treated patients versus $50.9 \%$ for delayed patients (log rank test: $p=0.001)$

Table 4 Cox proportional hazards model investigating factors associated with 1 year mortality

\begin{tabular}{|c|c|c|}
\hline$n=317$ & Hazard Ratio (CI) & $p$ value \\
\hline \multicolumn{3}{|c|}{ Treatment category } \\
\hline Timely treated & Reference & \\
\hline Delayed & $0.65(0.43-0.99)$ & 0.043 \\
\hline \multicolumn{3}{|l|}{ Mobiliy score } \\
\hline Unassisted & Reference & \\
\hline Assisted & $0.45(0.28-0.70)$ & $<0.001$ \\
\hline Unable & $1.00(0.59-1.72)$ & \\
\hline \multicolumn{3}{|l|}{ Tumor prognosis } \\
\hline Favorable & Reference & \\
\hline Moderate & $0.17(0.09-0.31)$ & $<0.001$ \\
\hline Unfavorable & $0.29(0.18-0.47)$ & $<0.001$ \\
\hline \multicolumn{3}{|l|}{ Age } \\
\hline Per year & $1.00(0.98-1.02)$ & 0.842 \\
\hline
\end{tabular}

\section{Conclusion}

In conclusion, the results from our study suggest delayed treatment of patients with symptomatic spinal metastases has both direct and indirect adverse consequences for functional performance status, quality of life and survival. Our results emphasize the need for early identification of patients with spinal metastases at risk of neurological deficits and optimization of referral patterns to prevent or minimize delayed referrals and treatment in the future. 
Funding Not applicable.

Data availability Not applicable.

Code availability Not applicable.

\section{Compliance with ethical standards}

Conflicts of interest None.

Open Access This article is licensed under a Creative Commons Attribution 4.0 International License, which permits use, sharing, adaptation, distribution and reproduction in any medium or format, as long as you give appropriate credit to the original author(s) and the source, provide a link to the Creative Commons licence, and indicate if changes were made. The images or other third party material in this article are included in the article's Creative Commons licence, unless indicated otherwise in a credit line to the material. If material is not included in the article's Creative Commons licence and your intended use is not permitted by statutory regulation or exceeds the permitted use, you will need to obtain permission directly from the copyright holder. To view a copy of this licence, visit http://creativecommons.org/licenses/by/4.0/.

\section{References}

1. Siegel RL, Miller KD, Jemal A (2017) Cancer statistics, 2017. CA Cancer J Clin 67:7-30. https://doi.org/10.3322/caac.21387

2. Walsh GL, Gokaslan ZL, McCutcheon IE et al (1997) Anterior approaches to the thoracic spine in patients with cancer: indications and results. Ann Thorac Surg 64:1611-1618. https://doi. org/10.1016/S0003-4975(97)01034-5

3. Cole JS, Patchell RA (2008) Metastatic epidural spinal cord compression. Lancet Neurol 7:459-466. https://doi.org/10.1016/s1474 -4422(08)70089-9

4. Al-Qurainy R, Collis E (2016) Metastatic spinal cord compression: diagnosis and management. BMJ 2539:i2539. https://doi. org/10.1136/bmj.i2539

5. Hoy D, March L, Brooks P et al (2014) The global burden of low back pain: estimates from the global burden of disease 2010 study. Ann Rheum Dis. https://doi.org/10.1136/annrheumdis-2013204428

6. Vos T, Barber RM, Bell B et al (2015) Global, regional, and national incidence, prevalence, and years lived with disability for 301 acute and chronic diseases and injuries in 188 countries, 1990-2013: a systematic analysis for the global burden of disease study 2013. Lancet 386:743-800. https://doi.org/10.1016/S0140 $-6736(15) 60692-4$

7. van der Linden YM, Vonk EJA, Dijkstra SPDS et al (2004) Prediction of survival in patients with metastases in the spinal column. Cancer 103:320-328. https://doi.org/10.1002/cncr.20756

8. Versteeg AL, Verlaan J-J, de Baat P et al (2016) Complications after percutaneous pedicle screw fixation for the treatment of unstable spinal metastases. Ann Surg Oncol 23:2343-2349. https ://doi.org/10.1245/s10434-016-5156-9

9. Bach F, Larsen BH, Rohde K et al (1990) Metastatic spinal cord compression. Acta Neurochir (Wien) 107:37-43. https://doi. org/10.1007/BF01402610
10. Laufer I, Rubin DG, Lis E et al (2013) The NOMS framework: approach to the treatment of spinal metastatic tumors. Oncologist 18:744-751. https://doi.org/10.1634/theoncologist.2012-0293

11. van Tol FR, Choi D, Verkooijen HM, Oner FC, Verlaan JJ (2019) Delayed presentation to a spine surgeon is the strongest predictor of poor postoperative outcome in patients surgically treated for symptomatic spinal metastases. Spine J 19(9):1540-1547. https ://doi.org/10.1016/j.spinee.2019.04.011

12. Bollen L, van der Linden YM, Pondaag W et al (2014) Prognostic factors associated with survival in patients with symptomatic spinal bone metastases: a retrospective cohort study of 1,043 patients. Neuro Oncol 16:991-998. https://doi.org/10.1093/neuon c/not318

13. Fisher CG, Andersson GBJ, Weinstein JN (2009) Spine focus issue. summary of management recommendations in spine oncology. Spine 34:S2-S6. https://doi.org/10.1097/BRS.0b013e3181 baae29

14. Versteeg AL, Verlaan J-J, Sahgal A et al (2016) The spinal instability neoplastic score impact on oncologic decision-making. Spine 42:S231-S237. https://doi.org/10.1097/BRS.0000000000 001822

15. Galgano M, Fridley J, Oyelese A et al (2018) Surgical management of spinal metastases. Expert Rev Anticancer Ther 18:463472. https://doi.org/10.1080/14737140.2018.1453359

16. Choi D, Crockard A, Bunger C et al (2010) Review of metastatic spine tumour classification and indications for surgery: the consensus statement of the global spine tumour study group. Eur Spine J 19(2):215-222

17. Norman G (2010) Likert scales, levels of measurement and the "laws" of statistics. Adv Health Sci Educ Theory Pract 15:625632. https://doi.org/10.1007/s10459-010-9222-y

18. Sullivan GM, Artino ARJ (2013) Analyzing and interpreting data from likert-type scales. J Grad Med Educ 5:541-542. https://doi. org/10.4300/JGME-5-4-18

19. Johnson D, Creech J (1983) Ordinal measures in multiple indicator models: a simulation study of categorization error. Am Sociol Rev 48:398-407

20. Guzik G (2016) Quality of life of patients after surgical treatment of cervical spine metastases. BMC Musculoskelet Disord 17:1-6. https://doi.org/10.1186/s12891-016-1175-8

21. de Ruiter GCW, Nogarede CO, Wolfs JFC, Arts MP (2017) Quality of life after different surgical procedures for the treatment of spinal metastases: results of a single-center prospective case series. Neurosurg Focus 42:E17. https://doi.org/10.3171/2016.6.FOCUS 16150

22. Schwartz CE, Stucky B, Rivers CS et al (2018) Quality of life and adaptation in people with spinal cord injury: response shift effects from 1 to 5 years postinjury. Arch Phys Med Rehabil 99:15991608.e1. https://doi.org/10.1016/j.apmr.2018.01.028

23. Choi D, Fox Z, Albert T et al (2015) Prediction of quality of life and survival after surgery for symptomatic spinal metastases: a multicenter cohort study to determine suitability for surgical treatment. Neurosurgery 77:698-708. https://doi.org/10.1227/ NEU.0000000000000907

24. Lee BH, Park JO, Kim HS et al (2014) Perioperative complication and surgical outcome in patients with spine metastases: retrospective 200-case series in a single institute. Clin Neurol Neurosurg. https://doi.org/10.1016/j.clineuro.2014.04.025

25. Helweg-Larsen S, Sorensen PS, Kreiner S (2000) Prognostic factors in metastatic spinal cord compression: a prospective study using multivariate analysis of variables influencing survival 
and gait function in 153 patients. Int J Radiat Oncol Biol Phys 46:1163-1169

26. Dea N, Versteeg A, Fisher C et al (2014) Adverse events in emergency oncological spine surgery: a prospective analysis. J Neurosurg Spine J Neurosurg Spine 21:698-703. https://doi. org/10.3171/2014.7.SPINE131007

27. Dasenbrock HH, Pradilla G, Witham TF et al (2012) The impact of weekend hospital admission on the timing of intervention and outcomes after surgery for spinal metastases. Neurosurgery 70:586-593. https://doi.org/10.1227/NEU.0b013e318232d1ee

28. Poortmans P, Vulto A, Raaijmakers E (2001) Always on a Friday? Time pattern of referral for spinal cord compression. Acta Oncol 40:88-91. https://doi.org/10.1080/028418601750071127

Publisher's Note Springer Nature remains neutral with regard to jurisdictional claims in published maps and institutional affiliations. 